\title{
VOCES AMERINDIAS EN LAS RELACIONES DE HERNÁN CORTÉS
}

\author{
José M. a Enguita Utrilla \\ Universidad de Zaragoza \\ A don Rafael Lapesa
}

\section{INTRODUCCIÓN}

1. La figura de Hernán Cortés ha dado lugar a una nutrida serie de investigaciones ${ }^{1}$; sin embargo, la personalidad de este extremeño nacido en Medellin (1485), lo mismo que su obra, ha quedado oscurecida y oculta - según sugiere Hernández Sánchez-Barba, pág. IX- "entre los vapores de la pasión y la polémica". Con todo, de Cortés se ha resaltado que no sólo representa el aspecto militar de quien va tras el botín, sino también al "hombre que vio en el indigena un semejante $y$ en la tierra conquistada una nueva patria" 2 .

Tales rasgos definidores del colonizador del imperio azteca se hallan explícitos en numerosos pasajes de sus Relaciones ${ }^{3}$ : ya al llegar a Cozumel,

1 Incluso, con carácter monográfico, ha sido tema central de reuniones científicas;

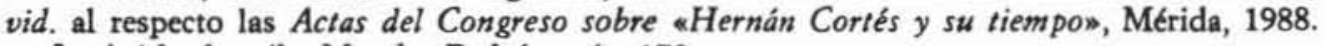

2 Asf lo describe Morales Padrón, pág. 170.

3 Los escritos de Hernán Cortés sobre los asuntos de la Nueva España no escasean; pero entre todos ellos destacan las cinco Relaciones que envió a Carlos I (10 de julio de 1519,30 de octubre de 1520,15 de mayo de 1522,15 de octubre de 1524 y 3 de septiem. bre de 1526), en las cuales relata la conquista del imperio mexicano. Utilizo en este trabajo dichas fuentes documentales a partir de su edición en Historiadores primitivos de Indias (I), Madrid, vol. XXII de la Biblioteca de Autores Españoles, 1925, págs. 1-153; en casos de lecturas dudosas he consultado, de las abundantes ediciones disponibles, la facsimilar llevada a cabo por J. Stummvoll, Ch. Gibson y F. Unterkircher a partir del Codex Vindobonensis S. N. 1600 (Graz, Akademische Druck-u. Verlagsanstalt, 1960); de esta última publicación proceden también los datos relativos a la memoria que acompaña a la primera Relación sobre el oro, plata, joyas y ropa enviados por Cortés al Emperador, ya que no consta en el tomo de la Biblioteca de Autores Españoles. En las páginas preliminares de ambas ediciones, que serán citadas con las abreviaturas M (Madrid) y G (Graz), encontrará el lector información sobre las vicisitudes que han corrido los escritos del conquistador de México. 
alude a uno de los objetivos esenciales de su empresa ("les dijo que no iban a hacerles mal ni daño alguno, sino para les amonestar y atraer para que viniesen en conocimiento de nuestra santa fe católica" M4a), motivo más ampliamente desarrollado en las Relaciones cuarta y quinta, donde solicita proveer a la Nueva España de "personas religiosas de buena vida y ejemplo" M114b 4; más que conquistador, Cortés ha sido considerado fundador, y ese talante se manifiesta abiertamente, por ejemplo, en la tristeza que le producen las crueldades de la guerra: "y que cierto me ponía en mucha lástima y dolor el daño que en ellos se hacía, y continuamente les hacía acometer por la paz" M86b; "y era tanta la grita y lloro de los niños y mujeres, que no había persona a quien no quebrantase el corazón, e ya nosotros teníamos más que hacer en estorbar a nuestros amigos que no matasen ni hiciesen tanta crueldad, que no en pelear con los indios" M88 $\mathrm{b}^{5}$; no ha de extrañar, desde esta perspectiva, la crítica no disimulada con que se refiere al proceso colonizador llevado a cabo en las Antillas: "porque todos, o los más, tienen pensamientos de se haber con estas tierras como se han habido con las islas que antes se poblaron, que es esquilmarlas y destruirlas, y después dejarlas; y porque me parece que sería gran culpa a los que de lo pasado tenemos experiencia, no remediar lo presente y por venir, proveyendo en aquellas cosas por donde es notorio haberse perdido las dichas islas, mayormente siendo esta tierra, como yo muchas veces a vuestra majestad he escrito, de tanta grandeza y nobleza $[\ldots]$, suplico a vuestra majestad las mande mirar" M116b117 a.

No faltan en las Relaciones comentarios sobre el carácter providencialista de los hechos de Indias ("si Dios misteriosamente no nos quisiera salvar, era imposible escapar de alli" M44a ; "y según la necesidad que teniamos, milagrosamente nos envió Dios este socorro" M64b ${ }^{6}$ ), sobre las disensiones internas entre los propios colonizadores ("Muchos caminos déstos se hubieran hecho en esta tierra, y muchos secretos della tuviera yo sabidos, si estorbos de las armadas que han venido no los hubieran impedido" M108b) ?.

Cortés, en fin, seguro de sus grandes servicios a la Corona española, pide con sutileza al Emperador los títulos que, en justicia, cree merecer: "Deseo, sin comparación, y no sin causa, que vuestra majestad sacra sea verdaderamente informado de mis servicios y culpas, porque tengo por fe, y no sin mérito, que por ellos me ha de mandar vuestra majestad católica muy grandes y crecidas mercedes, no habiendo respecto a lo poco que mi pequeña vasija

4 Vid. asimismo M115ab, M116b y M151a.

5 Vid. también M85b y M87a.

- Otros fragmentos en M17b, M85a, M86a, M134b.

7 Entre dichos estorbos, menciona el herraje de esclavos realizado por un bachiller Moreno en tierras hondurefias; vid. M142b. 
puede contener, sino a lo mucho que vuestra celsitud es obligado a dar a quien $\tan$ bien y con tanta fidelidad sirve como yo le he servido" M149b.

2. Si todos estos fragmentos son valiosos para trazar el carácter humano de Hernán Cortés, no es menos cierto que sus escritos tienen un indudable interés para observar las primeras alteraciones de la lengua española al entrar en contacto con las culturas del imperio azteca. Igual que Cristóbal Colón, el conquistador de México — según ha señalado Gallego Morell, pág. 33- "no cuenta en sus cartas la relación de su tarea, sino que transmite lo que sus ojos ven" ${ }^{8}$. Esa visión, lógicamente, va acompañada de la imagen de la metrópoli (" [...] al mercado de Temixtitan, que es una plaza harto mayor que la de Salamanca" M78b; "Hay hombres como los que llaman en Castilla ganapanes, para traer cargas" M32a) y de la experiencia acumulada en otras zonas ya colonizadas ("Crian muchas gallinas como las de Tierra-Firme, que son tan grandes como pavos" M9b); tiene su expresión más transparente en la designación patrimonial que reciben los territorios descubiertos ("Por lo que yo he visto y comprehendido cerca de la similitud que toda esta tierra tiene a España $[\ldots]$, me pareció que el más conveniente nombre para esta dicha tierra era llamarse la Nueva España del mar Océano; y así, en nombre de vuestra majestad se le puso aqueste nombre" M52a) y en la fundación de Medellin, en recuerdo de la patria de Hernán Cortés ("que ficiese una villa de españoles en la provincia de Tuxtebeque, y que le pusiese nombre de Medellin” M91b; M96a). Pero, a menudo, da paso a la expresión de asombro ante las novedades que ofrecen las tierras exploradas: "Porque para dar cuenta $[\ldots]$, no podré yo decir de cien partes una de las que dellas se podrían decir; mas como pudiere, diré algunas cosas de las que vi, que aunque mal dichas, bien sé que serán de tanta admiración, que no se podrán creer, porque los que acá con nuestros propios ojos las vemos, no las podemos con el entendimiento comprehender" M31b ${ }^{9}$.

Ello implica también, necesariamente, la existencia de limitaciones lingüísticas, para cuya solución uno de los procedimientos a los que recurren los colonizadores consiste en la adopción de préstamos léxicos tomados de las lenguas indígenas. Las Relaciones aportan ya la primera colección conocida de voces nahuas; además, contienen vocablos de las Antillas aplicados a las cosas de la Nueva España, de igual modo que ocurre en las fuentes documentales referidas a otras zonas del Nuevo Mundo.

- Vid. además Diario, pág. 71.

- Para otros pasajes sobre el tema, vid. M22a, M33a, M35b, M90a y M131b. 
INVENTARIO DE INDIGENISMOS

3. acal 'embarcación de remo' ("y vieron cómo todos los naturales della la desamparaban, y unos con sus haciendas se iban a meter en la laguna con sus canoas, que ellos llaman acales" M57a). Voz procedente del náhuatl (atl 'agua' y calli 'casa'), según reconocen Molina, Simeon, Robelo, Friederici, Macazaga y Cabrera; consta en las Décadas de Pedro Mártir, en la Historia de Fernández de Oviedo, Las Casas y Díaz del Castillo; la registra ya Covarrubias. No se emplea modernamente, por lo que los lexicógrafos la recogen como forma histórica ${ }^{10}$, anulada por el antillanismo canoa, lo que ya resulta patente en las Relaciones de Cortés: frente a los 166 testimonios de canoa que se han anotado, sólo un ejemplo de acal que, además, se presenta como equivalente del término arahuaco.

4. aje 'especie de batalla o name, Batatas edulis, Batatas xanthorhiza Chois.' ("porque habian hallado muchos maizales, aunque no muy grandes, y ages, que es un mantenimiento con que los naturales de las islas se mantienen" G234r [agoe M121b]; G16r [cuyes M9b], G236r [agro M123b]). Confirman la procedencia taína de este vocablo, señalada ya por Hernán Cortés, Tejera, Henriquez Ureña (Ant., pág. 178; Ind., pág. $108^{11}$ ), Friederici, DCECH y Buesa $\S 41$. Es uno de los pocos indoamericanismos que aparecen en los escritos del primer Almirante de Indias (Diario, págs. 81-83); después se testimonia en las Décadas de Mártir de Anglería, Sumario e Historia de Oviedo, Las Casas, Castellanos e incluso en el teatro de Tirso de Molina (García Blanco, pág. 199). Según Pichardo, MLéx. y Henríquez Ureña (SDgo., pág. 122), la palabra ha quedado anticuada, pues desde el siglo xvir fue sustituida por batata y ñame; no obstante, los lexicógrafos proporcionan algunas referencias actuales para Cuba, Perú (DMA) y Panamá (Amado, pág. 95).

5. aji 'variedad de pimiento muy picante, Capsicum sp.' ("cada una llevaba cuarenta anegas de maíz y diez hombres, sin otras muchas cosas de frísoles y aji y cacao" M137b; M139a; jaji M137a [xaxi G252v] ${ }^{12}$ ). Los estudiosos están de acuerdo en la filiación taina de esta voz (vid. Tejera, Henríquez Ureña (Ant., pág. 178; Ind., pág. 109), Friederici, DCECH y Buesa

10 Dato que confirma Lope Blanch, págs. 84-85, en su estudio de los indoamericanismos en la norma culta de la ciudad de México: acal aparece con una respuesta, que pertenece, sin duda, al vocabulario cultural pasivo de uno de los informantes. 59-86.

${ }^{11} \mathrm{Vid}$. en esta obra el pormenorizado capítulo titulado $* \mathrm{El}$ enigma del aje», págs.

12 El texto es, no obstante, de lectura difícil. 
§ 22); se documenta en Colón (Diario, pág. 83), Décadas de Pedro Mártir, Sumario e Historia de Oviedo, Díaz del Castillo, Castellanos, Acosta, Valdivia $\mathrm{y}$ en otras fuentes del periodo virreinal (vid. Boyd-Bowman, ZMunné y Mejias). Hoy es forma léxica muy difundida en las Antillas y en América del Sur, según recuerdan MLex., DMA, Neves y Sala.

6. bejuco 'nombre genérico con que se conocen diversas plantas sarmentosas, empleadas como ligaduras y cuerdas, Aristolochia, Bignonia, etc.' ("y por alli pasábamos con tanto peligro asidos por unos bejucos que también se ataban de una parte a otra" M131b). La opinión más extendida hace proceder esta forma léxica del taíno (Tejera, Henríquez Ureña (Ant., pág. 182; Ind., pág. 103), Friederici, DCECH y Buesa § 24). Se atestigua en las Décadas de Pedro Mártir; además, en las Relaciones de Yucatán (Alvar, pág. 179), en la obra de Fernández de Oviedo, Castellanos, Acosta, Góngora Marmolejo, La Araucana (Morínigo, pág. 95) y en otros documentos de los siglos XVI y xvir presentados por Boyd-Bowman, ZMunné y Mejías; es utilizada tempranamente por escritores peninsulares, pues se registra en Lope de Vega (Morínigo, Ind., pág. 42) y Tirso de Molina (García Blanco, pág. 200); pasaría también al Diccionario de Autoridades. Hoy es palabra que pertenece al español general (vid. MLex., DMA, Neves, Sala y DRAE); Alvar, en su estudio sobre las Elegias de Juan de Castellanos, observa su presencia mediante encuestas directas en México, Guatemala, Costa Rica, El Salvador, Santo Domingo, Puerto Rico, Colombia, Ecuador, Perú, Bolivia y Argentina; no obstante, en la lengua literaria, según indica Buesa $§ 24$, va siendo reemplazada por el galicismo liana.

7. cacaguatal 'plantío de cacao' ("donde ellos estaban tenía él ciertos vasallos suyos, que le servían de ciertos cacaguatales, porque era aquella tierra muy buena de ellos" M130a; G245r [cacagüetales M131a]; G251r [caguatales M135b]; G253r [cagüetales M137b]). De acuerdo con los comentarios que hace Cortés en sus Relaciones, este derivado remite a cacao y no a cacahuate, producto que no se nombra en sus escritos; Fernández de Oviedo emplea también esta voz con el mismo significado ("la tierra era tan montuosa y llena de cacaguatales, que son aquellos árboles que la fructa se trata $e$ corre por moneda", Historia, 3, 476); con la acepción de 'terreno sembrado de cacahuates' se documenta posteriormente. en Bernal Díaz del Castillo. Las dificultades en torno al valor semántico del vocablo no han terminado aún: Santamaría considera erróneo relacionar cacahuatal con cacaotal 'plantación de cacao' en el español mexicano actual. Acepta, sin embargo, que este último significado pueda darse en América Central, según señala el DMA entre otros trabajos; vid. asimismo sobre esta cuestión Robelo, DGA y Cabrera, quienes 
además ofrecen la base náhuatl cacáhuatl, a la que se ha unido el sufijo español $-a l$.

8. cacao 'árbol de la familia de las esterculiáceas, Theobroma cacao $L$.; su fruto' ("porque, como es tiempo agora de coger el cacao, estorban los de Culúa con las guerras" M69b; M119b, M124a, M127b, M131b, M132b, M137a, M137b, M138a ; cacap M28b [G51r]). Término de filiación náhuatl (cacahua, forma radical de cacáhuatl), según Molina, Simeon, Friederici, Macazaga, Cabrera, DCECH y Buesa $\S 56$; otros autores, entre ellos Barrera, consideran que se trata de un préstamo maya adoptado por los nahuas y acomodado al patrón morfológico de su lengua. Se documenta en las Décadas de Pedro Mártir, en la Historia oviedense, Las Casas, Díaz del Castillo, Acosta y en otros textos de los siglos xvi y xvir recopilados por Boyd-Bowman, ZMunné y Mejías; ya aparece como entrada en Autoridades; el vocablo es en la actualidad panhispánico y se ha difundido también a otras lenguas.

9. cacique 'jefe, reyezuelo' ("que los caciques de aquella isla $[\ldots]$, habían dejado los pueblos" M4a; M4b, M5b, M6a, M7a, M7b, M8a, M11a). Cortés únicamente emplea esta palabra en la primera Relación, es decir, al inicio de la conquista de México. En este mismo texto ya se utilizan equivalentes patrimoniales (indio principal M4b, señor de la isla M4b, aquel cacique señor de la isla M4b), que son exclusivos en las Relaciones posteriores (señor de aquel valle $\mathrm{M} 15 \mathrm{a}$, el mayor señor de todos M19a, el señor del lugar M23b, doce señores muy principales M23b, un gran señor M23b, personas principales $\mathrm{M} 50 \mathrm{a})$. La voz ha sido profusamente comentada y gran parte de los investigadores está de acuerdo en su ascendencia taína: los Perea, págs. 4648, apuntan el étimo kassikoan 'habitar, tener casa', verbo arahuaco cuyo formante final -oan 'permanecer largo tiempo, perdurar' tiene su parónimo en el tupí -oane; vid. asimismo Tejera, Henríquez Ureña (Ant., pág. 182; Ind., pág. 113), Friederici, DCECH y Buesa $\S 18$. Ya es utilizada por Colón (Diario, pág. 83) y después consta sin apenas excepciones en los textos primitivos de Indias (Décadas, Sumario e Historia de Oviedo, Las Casas, Cieza de León, Díaz del Castillo, Castellanos, Valdivia, etc.); se atestigua también tempranamente en autores peninsulares: Lope de Vega (Morínigo, Ind., pág. 31), Tirso de Molina (García Blanco, págs. 204-205), Covarrubias y Autoridades. El antillanismo pasó al español general con el significado de 'jefe indio'; existen, por otra parte, numerosas acepciones nuevas, de las cuales se encuentran difundidas por todo el ámbito hispanohablante - y en lenguas pertenecientes a otras culturas - las dos siguientes: 'persona que en su pueblo o comarca ejerce excesiva influencia en asuntos políticos o admi- 
nistrativos' y 'déspota, tiranuelo, arbitrario, mandón' (vid. DMA, Neves, Sala y DRAE).

10. caimán 'cocodrilo americano, Crocodilus americanus' ("tres plumajes de colores que son de una cabeza grande de oro que parece de caimán" G20r). Aunque Tejera incluye esta palabra en su vocabulario indigena de Santo Domingo, los lexicógrafos se inclinan, no sin cautela, a emparentarla con el caribe: vid. Henríquez Ureña (Ant., pág. 185; Ind., pág. 106), DCECH y Buesa $\S 32$. Se anota en la Historia de Fernández de Oviedo, en Castellanos, Acosta y en otros textos de los siglos xVI y xvir examinados por Boyd-Bowman, ZMunné y Mejías; pronto fue conocida en la Peninsula, pues la emplean Lope de Vega (Morínigo, Ind., pág. 18) y Tirso de Molina (Garcia Blanco, pág. 192); se incluye también en el Tesoro de Covarrubias y en Autoridades. Hoy pertenece al español general (MLex., DMA, Sala y DRAE) y ha pasado asimismo a otras lenguas de cultura.

11. canoa 'embarcación de remo, normalmente de una sola pieza' (" $y$ entraron veinte indios en una canoa" M3a; "supo de tres indios que se tomaron en una canoa" M4a; M4b, M5a, M6a, M23a, M23b, M41a, M44a, M57a, etc. ; canoita M124b, M129b; canoilla M125a; canoa chiquita M129a). Es la voz indígena más repetida en las Relaciones, con 166 registros. Cabe advertir que el conquistador de México separa claramente el significado de este vocablo del que tiene el término patrimonial barca ("me meti en el bergantín que ya tenía acabado y en dos barcas y cuatro canoas" M135a), aunque no ofrece rasgos diferenciadores de estas embarcaciones. En cuanto a su filiación lingüistica, hay que recordar que los Perea, págs. 89-92, encuentran este lexema en dialectos caribes y arahuacos; vid. asimismo Friederici y el breve artículo de Taylor, págs. 242-244, en el que concluye que canoa posee seguramente una base arahuaca; parecida opinión manifiestan Tejera, Henríquez Ureña (Ant., pág. 182; Ind., pág. 104), DCECH y Buesa $\S 7^{13}$. Es término utilizado ya por Colón (Diario, pág. 82) y después se testimonia en las Décadas de Mártir de Angleria, Relaciones de Yucatán (Alvar, pág. 178), Sumario e Historia de Fernández de Oviedo, Las Casas, Diaz del Castillo, Castellanos, Acosta, Góngora Marmolejo y en otros muchos textos virreinales; se encuentra asimismo en el Vocabulario de Nebrija, en Lope de Vega (Morínigo, Ind., pág. 19), Tirso de Molina (García Blanco, pág. 193), Covarrubias y Autoridades. Hoy ha pasado al español general y a otros idiomas ${ }^{14}$.

\footnotetext{
13 Vid. otros comentarios sobre este antillanismo en Cuervo, págs. 120-122, y Calcaño, págs. $712-714$.

14 Incluso ha penetrado en otras lenguas indigenas del Nuevo Mundo: asf, en el territorio guaranf ha reemplazado a igara, forma hoy completamente desusada (vid. Hispanismos, pág. 225).
} 
12. ciguacoat 'lugarteniente' ("tornéle a dar el mismo cargo que en tiempo del señor tenía, que es ciguacoat, que quiere tanto decir como lugarteniente del señor" M110a). Sólo en contadas excepciones hacen los estudiosos referencia a este vocablo, de clara ascendencia náhuatl. Robelo, Simeon y Cabrera lo relacionan con cíhuatl 'mujer' y cóatl 'culebra, serpiente', y le dan dos acepciones: 'magistrado que era una especie de virrey o lugarteniente de los emperadores mexicanos' ${ }^{15}$, conforme con el texto de Hernán Cortés que repite la Historia oviedense, y 'nombre de la diosa Quilaztli, madre del género humano'. Es voz histórica.

13. coa 'palo puntiagudo, de madera recia, utilizado para cavar la tierra' ("por tanto, que hiciesen venir mucha gente de sus labradores, y trujesen sus coas, que son unos palos, de que se aprovechan tanto como los cavadores en España de azada" M83b). Término proveniente del arahuaco insular, según los Perea, págs. 86-88, Tejera, Henríquez Ureña (Ant., pág. 183 ; Ind., pág. $115)$, Friederici, DCECH y Buesa $\S 15$. Se documenta en la Historia de Fernández de Oviedo y en otras fuentes de los siglos xvi y xvir analizadas por Boyd-Bowman, ZMunné y Mejías. En la actualidad pervive en algunas áreas hispanoamericanas, particularmente en las Antillas, México, Panamá y Venezuela (vid. DMA, Neves, Sala y DRAE).

14. guarique 'pendiente' ("Más dos guariques grandes de pedreria azul, que son para poner en la cabeza grande del caimán" G20r). El vocablo se atestigua en el contexto geográfico de Yucatán (primera Relación); lo mismo ocurre en la Historia de Fernández de Oviedo, cronista que lo emplea junto a otros como calachuni 'señor', de clara ascendencia maya, por lo que probablemente haya que afiliarlo a dicha modalidad lingüística. No consta en otros trabajos consultados.

15. haba 'cesta' ("hay una haba de caña" G20r). Según los Perea, págs. 110-111, este término procede de un radical arahuaco-taino; vid. en este sentido Tejera, Henríquez Ureña (Ant., pág. 182; Ind., pág. 114), Friederici, DCECH y Buesa $\S 16$. Se encuentra en el Sumario y en la Historia de Fernández de Oviedo, en Las Casas y en otros textos virreinales estudiados por Boyd-Bowman. La grafia $h$ debió representar una aspiración que ha subsistido en las hablas actuales de las Antillas, México, América Central, Venezuela, Colombia, Perú, Chile y Bolivia, donde se conoce la voz (vid. DGA, DMA, Neves, Sala y DRAE).

15 Estas bases léxicas parecen estar presentes también en el nombre propio Ciguacoacin, «uno de los más principales [de Temixtitan], capitán y gobernador de todos ellos» M89a. 
16. iguana 'reptil saurio de gran tamaño con una cresta dentada a lo largo del lomo, Iguana tuberculata Luur.' ("y traían muerto un león y ciertas iguanas, que son unos grandes lagartos que hay en las islas" M130b). Reconocen la procedencia taína de este indigenismo Tejera, Henriquez Ureña (Ant., pág. 182; Ind., pág. 103), DCECH y Buesa $\S 9$; otros estudiosos como Taylor (Iwana, pág. 157) ${ }^{16}$ y Neves lo adscriben al caribe. Posee abundantes testimonios en los textos cronisticos: Décadas de Mártir de Anglería, Relaciones de Yucatán (Alvar, pág. 178), Sumario e Historia de Fernández de Oviedo, Díaz del Castillo, Castellanos, Acosta y otros textos de los siglos XVI y xVII recopilados por Boyd-Bowman, ZMunné y Mejías; aparece también en el teatro de Tirso de Molina (García Blanco, pág. 200) y en Autoridades. El término está difundido actualmente desde México hasta el área rioplatense (DGA, MLex., DMA, Sala y DRAE) e incluso ha pasado al español peninsular ${ }^{17} \mathrm{y}$ a otras lenguas.

17. maguey 'nombre genérico de numerosas plantas americanas que, en su mayoria, tienen fibras en las hojas y jugo en el cogollo, Agave americana $L$., etc.' ('Venden miel de abejas y cera y miel de cañas de maíz, que son tan melosas y dulces como las de azúcar, y miel de unas plantas que llaman en las otras y en éstas maguey, que es muy mejor que arrope; y destas plantas facen azúcar y vino, que asimismo venden" M22b). Los Perea, págs. 103104 , incluyen esta palabra dentro del léxico taino; vid. también Tejera, Henríquez Ureña (Ant., pág. 182 ; Ind., pág. 103 ), DCECH y Buesa $§ 25$. Su documentación no escasea: se anota en las Décadas de Mártir de Anglería, Relaciones de Yucatán (Alvar, pág. 179), Historia oviedense, Las Casas, Diaz del Castillo, Castellanos, Acosta y en otros escritos de los siglos xvi y xvir (Boyd-Bowman, ZMunné. Mejias), y ya aparece en Autoridades. Su difusión por tierras continentales del Nuevo Mundo relegó en éstas el empleo de los indoamericanismos equivalentes, de modo que hoy es forma léxica extendida por toda la América del Sur (vid. MLex., DMA, Sala y DRAE) ${ }^{18}$.

18. maiz 'cereal comestible, Zea Mays L.' ("y trujeron ciertas gallinas y un poco de maiz" M6a; "La tierra es muy buena y muy abondosa de comida, así de maiz como de fruta" M7ab; M9b, M28b, M34b, M38a, M45a,

16 En realidad, anota el étimo caribe iwana, aunque indica que la lengua originaria es el taíno.

${ }_{17}$ Asl se refleja en la publicación que recoge los datos allegados en las Encuestas léxicas del habla de Madrid (ed. de J. C. de Torres), para el proyecto del Estudio coordinado de la norma lingüistica culta de las principales ciudades de Iberoamérica y de la Peninsula Ibérica; iguana fue respuesta mayoritaria de los informantes seleccionados (núm. 4.268).

18 Según la noticia que proporcionan estos trabajos lexicográficos, aunque se conoce en Bolivia, Paraguay, Uruguay y Argentina, en estos países se utiliza muy poco. 
M59b, M71b, etc.; maiz en grano $y$ en pan M32b; maiz seco M121a, M135b, M136b, M137a; maiz tostado y cocido M45b; maiz verde M135b, M136b; cañas de maiz M32b; tortas de pan de maiz M63a). El origen taino de este término no ofrece dudas para Henríquez Ureña (Ant., pág. 182 ; Ind., pág. $103)$, Friederici, DCECH y Buesa $\S 21^{19}$. Su presencia en textos castellanos data ya del tercer viaje de Colón (vid. Apuntaciones, § 980) y es constante en los siglos xvi y xvir (Décadas de Pedro Mártir, Sumario e Historia de Fernández de Oviedo, Cieza de León, Las Casas, Díaz del Castillo, Castellanos, Acosta, etc.), atestiguándose además en Lope de Vega (Morínigo, Ind., pág. 20), Tesoro de Covarrubias y en Autoridades. El nombre es hoy universalmente conocido y, en lo que concierne a América, de él han surgido abundantes acepciones secundarias, derivados y agrupaciones sintagmáticas (vid. DMA, Neves, Sala y DRAE) ${ }^{20}$.

19. maizal 'campo de maiz' ("sin ningún detener ni grita se metieron por los maizales, de que toda la tierra estaba casi llena" M17a; M101a, M121a, M121b; labranza de maizales M121a, M135b, M138b). Derivado de maiz, que se testimonia en las Relaciones de Yucatán (Alvar, pág. 178), Sumario e Historia de Oviedo y en otros escritos de los siglos xvi y xvIr (BoydBowman, ZMunné, Mejías), así como en la obra de Tirso de Molina (García Blanco, pág. 196) y en Autoridades.

20. ochilobus 'dios de la guerra' ("que por qué yo así brevemente no los acababa de matar y los quitaba de penar tanto, porque ellos tenían deseos de morir y irse al cielo para su Ochilobus que los estaba esperando para descansar; y este ídolo es el que en más veneración tienen" M87b). Según Robelo, esta voz deriva de huitzilin 'colibri' y opochtli 'izquierdo, sangriento', étimos que separadamente ya constan en Molina. Con las variantes archilobo, ochilobo, orchilobo y uchilobo, el nahuatlismo aparece también en la Historia de Fernández de Oviedo, a veces con el sentido de 'templo, casa de oración', equivalente al mayismo $c u$ y derivado de la acepción originaria, según comenta el cronista madrileño ${ }^{21}$.

\footnotetext{
19 El elemento radical de este indigenismo pertenece, de todos modos, a numerosas lenguas del área antillana, según observa Montes, pág. 33.

20 Para ésta y otras denominaciones españolas de la planta y su fruto, vid. García Mouton, págs. 121-126.

31 *Que vino de la parte del Norte haçia la provincia de Pánuco un capitán que llamaban Orchilobos, con quatrocientos hombres bien ordenados a su modo, con armas de plata e de oro, estando los de México en guerra con los de Tascala, e que se metió a ayudar a los de México en la guerra, los quales por su industria y esfuerço fueron vençedores; e que viendo el lugar aparejado en una laguna que alli era, la qual tenía una estrecha entrada de peñas, que yba a una isleta o roca de peña que estaba quassi isla en medio de
} 
21. panicap 'bebida indígena' ("E trajéronme diez platos de oro y mil y quinientas piezas de ropa, y mucha provisión de gallinas y panicap, ques cierto brebaje que ellos beben" M21b [panicacap G37v] ${ }^{22}$ ). El término probablemente esté relacionado con el radical verbal pania nitla 'echar salsa de aji o de miel sobre las poleadas, atolli o pinolli', que recogen Molina y Simeon. Lo utiliza Fernández de Oviedo cuando, en su Historia, trata de la Nueva España. No hay más referencias al vocablo en otros trabajos consultados.

22. tianguizco 'mercado' ("habia tres calles dende lo que teniamos ganado, que iban a dar al mercado, al cual los indios llaman Tianguizco" M79b). Voz de indiscutida procedencia náhuatl, según reconocen Molina, Simeon, Robelo, Macazaga, Cabrera, Friederici y Buesa $\S 45$. Se testimonia en las Relaciones de Yucatán (Alvar, pág. 181), Historia de Fernández de Oviedo, Díaz del Castillo y en otros textos de los siglos xvi y xvil examinados por Boyd-Bowman, ZMunné y Mejías. La acepción originaria ha quedado anticuada en México, pero el vocablo tianguis todavía se utiliza en este país con el valor de 'feria, compra y venta de mercaderias o productos que en un determinado día de la semana se hace en algunos pueblos del interior' (DGA, Santamaria, DMA, Sala y DRAE); en su capital, Lope Blanch, pág. 91, señala que ha adquirido la acepción especial de 'plaza'. Neves, por otra parte, amplía la difusión del indigenismo a América Central ('mercado pequeño', 'puestecito de venta'); además, se encuentran en los diccionarios generales alusiones a la utilización de tiangue 'mercado de ganados' en Ecuador y, hasta el siglo pasado, en Chile y Perú.

Cita Cortés, asimismo, la palabra Tlaltelulco, que podría interpretarse como 'lugar donde se instala el mercado' (" $\mathrm{y}$ a todo aquel sitio donde está [el mercado] llámanle Tlaltelulco" M79b; Tatebulco M81a, M86a); de hecho, así lo interpreta Fernández de Oviedo ${ }^{23}$; sin embargo, este último nombre corresponde más bien a una denominación toponímica, referida a una antigua colonia mexicana que estaba situada en una de las islas del lago Texcoco y fue unida a la capital; su mercado, que entró en decadencia tras la conquista, era el más importante, a juicio de los historiadores.

23. yuca 'planta euforbiácea con rizoma harinoso, Manihot utilissima Pohl.' ("Hallóse en él mucho maíz, mucho más granado que lo de atrás, y

\footnotetext{
la laguna, començó a habitar con su gente, e hiço una pequeña torre de piedra, que después quedó por templo mayor de Orchilobos, consagrado a su nombrew (Historia, 3, 531; vid. también 3, 528-529).

as Dudosa parece también, a la vista de la edición facsimilar, la interpretación pan y cacao de Hernández Sánchez-Barba, 52.

${ }_{23}$ «E a todo aquel sitio donde está el tracto de lo que se vende e compra llámanle catebulcow (Historia, 3, 399).
} 
yuca [...]" M123b; M9b $\left.{ }^{24}, \mathrm{M} 121 \mathrm{~b}\right)$. El parentesco taíno de esta voz es reconocido por numerosos estudiosos: además de los Perea, pág. 120, vid. Tejera, Henríquez Ureña (Ant., pág. 184; Ind., pág. 117), Friederici, DCECH y Buesa $\S 21$. Su documentación no escasea: según Corominas, el primer registro data de 1495; posteriormente se anota en las Décadas de Pedro Mártir, Relaciones de Yucatán (Alvar, pág. 163), Sumario e Historia de Fernández de Oviedo, Las Casas, Díaz del Castillo, Castellanos, Acosta y en otros textos del periodo virreinal reunidos por Boyd-Bowman, ZMunné y Mejías; aparece también en Tirso de Molina (Garcia Blanco, pág. 196) y en Autoridades. El indigenismo vive hoy en Hispanoamérica junto al producto al que designa, más conocido en las áreas tropicales (DGA, MLex., DMA, Neves, Sala y DRAE); ha pasado asimismo al español peninsular ${ }^{25}$ $\mathrm{y}$ a otras lenguas de cultura.

24. Aparte de las formas léxicas enumeradas, en las Relaciones de Cortés se registran otros significantes de origen americano: entre ellos se encuentran gentilicios aplicados a varios grupos étnicos (chichimecas M152b, guanajos M147a, guastecas M103b, impilcingos M112a, mixes M109a, tlascaltecas M22b-los de Tascaltecal M76b-indios de Tascaltecal M86b, otumies M82a, M82b, M83a-utumies M75b, M76b, zapotecas M109a-zaputecas M152a) ${ }^{26}$ y numerosas designaciones onomásticas, algunas de las cuales constituyen propiamente la aplicación de sustantivos comunes a personajes indígenas ("y en ella venía por capitán, con otros diez mil hombres de guerra muy bien aderezados, Chichimecatecle, que es de los principales señores de aquella provincia" M61b; "que el otro su compañero, que se llama Mazatl, era más parte con la comunidad, y que éste no consentía" M145b) ${ }^{27}$ y a divisiones geográficas ("para le enviar por la costa del norte a poblar la punta o cabo de Hibueras" M103a; M114b; Higueras M152b [Hibueras G286v] ; Higuetas M118a [Hibueras G230r]) ${ }^{28}$.

24 Se transcribe potu yuca en M9b; la lectura de G16r no mejora esa extraña variante; Hernández Sánchez-Barba, pág. 23, interpreta el texto como patata yuca.

${ }_{25}$ También en este caso los informantes para las Encuestas léxicas del habla de Ma. drid demostraron conocer la palabra, pues contestaron a esta pregunta (núm. 4.183) con el nombre antillano, si bien en alguna respuesta se precisó que el producto es propiamente americano.

${ }_{28}$ Vid. Cabrera, s. vv., para etimología y otros datos acerca de la mayor parte de las denominaciones enumeradas.

27 Para Chichimecatecle, vid. Cabrera, quien explica la palabra a partir de chichimeca 'color rojizo' y teuctli 'jefe'; en cuanto a Mazatl, consta ya en Molina con el significado de 'ciervo'; por otro lado, vid. § 12, n. 15, para Ciguacoacin.

28 Sobre la filiación lingǘstica de bibuera 'planta que da por fruto una calabaza cilíndrica, Crescentia cujete, Lagenaria vulgaris; su fruto', que en los textos coloniales se presenta a veces con las variantes bigüera e bigüero, no discrepan demasiado los lexic6grafos - asi el DMA - al establecer su origen antillano. 


\section{OBSERVACIONES SOBRE EL INVENTARIO LÉXICO}

25. En total se han recogido 21 indoamericanismos, que corresponden a 19 bases léxicas ${ }^{29}$; la mayor parte pertenece a las lenguas de las Antillas, y especialmente al taíno: aje, aji, bejuco, cacique, caimán, canoa, coa, haba, iguana, maguey, maíz (maizal) y yuca ${ }^{30}$. El elemento léxico antillano no faltará tampoco en textos posteriores correspondientes a la Nueva España: Díaz del Castillo, en un conjunto de 80 indoamericanismos, inserta 30 de esta procedencia ${ }^{31}$; Lope Blanch (Ant., págs. 166-168) logra reunir 72 vocablos de la misma filiación extraídos de documentos mexicanos del siglo xvi y de comienzos de la centuria siguiente ${ }^{32}$; Alvar (Español, pág. 13) ha hecho una valoración general de la importancia del vocabulario antillano en la formación de las hablas hispanoamericanas, con referencias explícitas a la Nueva España: "Pienso, por ejemplo, cómo el castellano se aindió en las Antillas y, aindiado, pasó al continente; por eso tantos y tantos términos arahuacos que el español difunde como si fueran patrimoniales, y las grandes lenguas indigenas que los aceptan, aunque tengan que olvidar el propio, como barbacoa, cacique, ceiba, guayaba, hamaca, en el español de México, [o] los tainismos que como entradas castellanas figuran en el Diccionario de fray Alonso de Molina."

Las restantes voces inventariadas pertenecen al náhuatl, salvo el probable mayismo guarique: acal, cacao (cacaguatal), ciguacoat, Ochilobus, panicap [panicacap] y tianguizco. Esta escasa colección contrasta, desde luego, con los 50 nahuatlismos que, según se ha indicado, aparecen en Díaz del Castillo, con los 200 mexicanismos recopilados por Lope Blanch (Ant., págs. 162-163) a lo largo del siglo xvi y en los primeros años del siglo xvir, o con las 76 bases léxicas de filiación náhuatl, que utiliza Fernández de Oviedo en su Historia ${ }^{33}$.

Se observa en las Relaciones diferente actitud ante los términos autócto-

29 Puesto que cacaguatal y maizal son derivados de cacao y maix, respectivamente. Se excluyen, en los comentarios que siguen, gentilicios y nombres onomásticos, aunque puedan tener su punto de partida en denominaciones comunes.

so De su parentesco idiomático informa algunas veces el mismo Cortés: «ajes, que es su mantenimiento con que los naturales de las islas se mantienen* M121b; «iguanas, que son unos grandes lagartos que hay en las islas» M130b, etc.

s1 Vid. el capitulo «Voces taínas y antillanas», págs. 33-36, del estudio de Alvar sobre la obra de Bernal Díaz del Castillo.

${ }_{33}$ En buena parte, estas palabras siguen vivas actualmente en México, como demues. tran los 21 lexemas antillanos recogidos por Lope Blanch, págs. 83-84, en la norma lingülstica culta de la capital de este país.

33 Trato de este tema en un artículo que aparecerá próximamente en las Actas del Segundo Encuentro de Lingüistas y Filologos de España y México, Salamanca, 1992. 
nos de acuerdo con su parentesco lingüístico: mientras los nahuatlismos van acompañados, sin excepción, de glosas explicativas para facilitar su comprensión a los lectores ajenos al contexto colonial ("canoas, que ellos llaman acales" M57a; "cacap, que es una fruta como almendras" M28b; "ciguacoat, que quiere tanto decir como lugarteniente del señor" M110a; "irse para su Ochilobus que los estaba esperando para descansar; y este idolo es el que en más veneración tienen" M87b; "panicap, que es cierto brebaje que ellos beben" M21b; "que iban a dar al mercado, al cual los indios llaman Tianguizco" M79b), los vocablos antillanos se tratan frecuentemente como patrimoniales del español y en pocas ocasiones se explica su valor nocional ("coas, que son unos palos, de que se aprovechan como los cavadores en España de azada" M83b; "iguanas, que son unos grandes lagartos" M130b; “maguey, que es muy mejor que arrope" M32b) ${ }^{34}$.

No hay que olvidar que, en 1520, la variedad del español antillano, dotada de especial prestigio por haber plasmado en ella los colonizadores sus primeras vivencias en el Nuevo Mundo ${ }^{35}$, debía resultar familiar a los participantes en la empresa de Indias, pues ineludiblemente hubieron de adaptar a ella sus usos lingüísticos particulares.

26. Sorprende, al observar las voces indigenas empleadas en las Relaciones, encontrar tan exiguo número de representantes nahuas: Cortés entabló contacto con las poblaciones autóctonas a través de lenguas, intérpretes o farautes - entre los que destaca la india Malinche, bautizada con el nombre de Marina- ${ }^{36} \mathrm{y}$, por otro lado, da muestras de sensibilidad hacia el entorno que le rodea: "los hombres traen tapadas sus vergüenzas, y encima del cuerpo unas mantas muy delgadas y pintadas a manera de alquizales moriscos" M9b; "porque es muy mayor que Granada [...], y muy mejor abastecida de las cosas de la tierra, que es pan y de aves y caza y pescado de los ríos, y

34 De modo más preciso, puede decirse que no hay referencias directas ni indirectas al significado de ají, cacique, canoa, caimán y baba y, en lo que concierne a los múltiples testimonios de maíz, sólo en una ocasión Cortés proporciona información complementaria ( «que es el pan y mantenimiento destas partes» M71b).

3s Vid. Zamora Munné, págs. 166-167.

36 «A la lengua que yo tengo, que es una india de esta tierra [...], le dijo otra [...] M20b; «Que se informase de aquella lengua que con él hablaba, que es Marina, la que yo siempre conmigo he traído, porque alli me la habían dado con otras veinte mujeres» M130a; las referencias a los intérpretes son abundantes: M2b, M3a, M4a, M4b, M5b, M6b, M7b, M13b, M16a, M33a, M48b, M56b, M57a, M64b, M83a, M89b, M90a, M103a, M106b, M121b, M129b, M133b, M134a, M137a, M139b, M141a, M142b, M144a. A través de los intérpretes también comprueba Cortés la diversidad lingüística de la Nueva Es. paña: $\alpha[\ldots]$ aunque no los entendfamos bien, ni ellos a nosotros, porque son de lengua diferente de los que hemos visto. Por señas y por algunas palabras que de aquella lengua entendía, les rogué que dos dellos fuesen con diez españoles» M137b; vid. igualmente M127b, M138b, M143a, M144ab. 
de otras legumbres y cosas que ellos comen muy buenas" M18b; "porque los honrados ciudadanos della todos traen albornoces encima de la otra ropa" M21a; "que trataban sus mercaderías, las que más por aquellas partes se tratan, entre ellas el cacao, ropa de algodón, colores para teñir, otra cierta manera de tinta con que se tiñen ellos los cuerpos para se defender del calor y del frío, tea para alumbrarse, resina de pino para los sahumerios de sus ídolos, esclavos, otras cuentas coloradas de caracoles, que tienen en mucho para el ornato de sus personas" M127b.

Sin embargo, nahuatlismos frecuentes en textos cronísticos posteriores, que en buena parte han pervivido hasta nuestros días, sólo se mencionan a través del léxico patrimonial: así ocurre, por ejemplo, con amanteca ("los oficiales de artes mecánicas, que hay muchos, viven por sus jornales" M110b), capulin ("nos proveían de algunos mantenimientos, de que teníamos harta necesidad, especialmente de pescado y de cerezas" M77b), galpón ("hallé un muy buen aposento nuevamente hecho, tal y tan grande, que muy cumplidamente todos los de mi compañía y yo nos aposentamos en él" M22b; M62b), hule ("unas gomas que hay en esta tierra, que parece mucho a ánime" M81a), milpa ("y fui a dar a una labranza de maizales, adonde, en una casita que en ella había, se tomaron tres mujeres y un hombre" M135b), papa ${ }^{37}$ ("E rogáronme que ficiese traer allí uno, como religioso, de los suyos, que yo tenía preso, el cual era como general de aquella religión" M43b), pulque ("bodegas de vino que ellos hacen, donde hallamos asaz tinajas dello" M101a) o tameme ("Hay hombres como los que llaman en Castilla ganapanes, para traer cargas” M32a).

Desde esta perspectiva, es nota destacable el empleo frecuente del sintagma de la tierra ${ }^{38}$ para precisar lo que, por medio de las palabras españolas, se quiere transmitir: bastimentos de la tierra M128b, cosas de la tierra M18b, frutos de la tierra M33a, M121a, M139a, mantenimientos de la tierra M119b, naturales de la tierra M145a, M145b, papel de la tierra M36b, M126b, señores de la tierra M143a, villas de la tierra M148a.

27. Cortés es consciente de sus limitaciones en lo que se refiere a la captación de términos autóctonos, y lo manifiesta abiertamente en la segunda Relación: "En los dichos mercados se venden todas cuantas cosas se hallan en toda la tierra, que demás de las que he dicho, son tantas y de tantas calidades, que por la prolijidad y por no me ocurrir tantas a la memoria, y aun por no saber los nombres, no las expreso" M32b.

37 Término proveniente de papatli 'cabellos enmarañados', que llevaban los ministros o sacerdotes de los f́dolos (vid. Molina).

38 Sobre este complemento nominal, vid. el pormenorizado articulo que le dedica Figueroa, págs. 354-377. 
No hay que olvidar, en este sentido, que las Relaciones constituyen el relato de un primer contacto - por ello, poco profundo- con los territorios de la Nueva España; y, sobre todo, hay que tener presente que la preocupación esencial de Hernán Cortés no tenía como meta la descripción de la naturaleza o de las costumbres indígenas, sino la conquista y pacificación del imperio azteca para la Corona española: de ahí que los intérpretes sirvan primordialmente para esa misión ("dándoles a entender por los farautes y lenguas que alli iban con nosotros, que no queríamos guerra, sino paz y amor con ellos" M6b; "y que algunos dellos parescía que si tuvieran lengua con que se entender con ellos, se apaciguaran" M142b) ${ }^{39}$ y, además, para iniciar la evangelización de las comunidades autóctonas ("por medio de una lengua y faraute que llevaba, les dijo que no iban a hacerles mal ni daño alguno, sino para les amonestar y atraer para que viniesen en conocimiento de nuestra santa fe católica" M4a); de ahí que las denominaciones de grupos étnicos, los nombres de persona y los topónimos - ya en su forma autóctona, ya con significante patrimonial- no escaseen; incluso las mismas voces amerindias atestiguadas en las Relaciones obedecen también, en gran parte, a este propósito fundamental: aje, aji, cacao (cacaguatal), maiz (maizal), panicap y yuca son designaciones aplicadas a mantenimientos que los expedicionarios van encontrando en su recorrido; los bejucos sirven como ligaduras para atravesar ríos, y las coas para preparar el terreno dentro de la estrategia militar, contexto en el que, asimismo, surgen habitualmente los vocablos canoa y acales; con referencia a las comunidades indígenas, pueden analizarse igualmente desde este punto de vista los términos inventariados: cacique, ciguacoat 'lugarteniente' y Ochilobus 'dios de la guerra'; incluso el tianguizco aparece como uno de los principales objetivos militares para la conquista de la capital azteca; y, en fin, caimán, guarique y haba constan como objetos tomados a los naturales que se envían, con la primera Relación, al Emperador ${ }^{40}$.

\section{Consideraciones finales}

28. Las Relaciones son, indudablemente, fuente imprescindible para conocer el talante humano de su autor y el desarrollo de la conquista y coloni-

39 De importancia notable para su empresa colonizadora, son los mapas y representaciones pictográficas que Cortés obtiene a través de los intérpretes («Todo el tiempo que yo allf estuve diome muy larga cuenta de los españoles que iba a buscar, y hízome una figura en un paño del camino que habla de llevar» M126b; «vino a mí muy secretamente una noche y me trujo cierta figura en un papel de lo de su tierra, y queriéndome dar a entender lo que significaba, me dijo [...]» M126b).

40 Unicamente se mencionan dos voces carentes de esa motivación: «y venían cuatro indios cazadores que habían tomado y trafan muerto un león y ciertas iguanas» M130b; «Venden miel de abejas [...] y miel de unas plantas que llaman en las otras y éstas ma. guey" M32b. 
zación de la Nueva España; desde la perspectiva filológica resultan asimismo de un valor innegable para comprobar la expansión del español antillano en las primeras décadas del siglo xvi y también, claro está, para observar los primeros préstamos nahuas en la lengua que los pobladores de México habían conformado en las islas del mar Caribe.

Son pocos los nahuatlismos - y, en general, los indoamericanismos- que contienen las Relaciones. Pero el caso de Hernán Cortés no constituye una excepción: Góngora Marmolejo incluye en su Historia de Chile (1575) 21 vocablos amerindios y, de ellos, sólo cuatro (chavalongo 'dolor de cabeza', dalca 'embarcación indigena', maque 'especie vegetal' y pello 'concha de la almeja') están afiliados al mapuche, lengua de las parcialidades étnicas asentadas en el área geográfica sobre la que trata ${ }^{41}$. Frente a los textos mencionados, surge la Verdadera historia (1575) de Bernal Díaz del Castillo, que permite registrar más de 80 indoamericanismos léxicos, o la Historia (1535, $1 .^{a}$ parte) de Fernández de Oviedo, que reúne casi 400 voces indígenas, 76 de ellas relacionadas con las lenguas de la Nueva España.

Tan diferentes actitudes ante los términos autóctonos son consecuencia, lógicamente, de circunstancias particulares: Díaz del Castillo, soldado como Hernán Cortés y como Góngora de Marmolejo, escribe desde la experiencia acumulada a lo largo de cincuenta y cinco años de estancia en tierras de la Nueva España ${ }^{42}$; Fernández de Oviedo presenta una visión totalizadora del Nuevo Mundo, en la que atiende no sólo a los hechos bélicos, sino también a la fauna, a la flora, a la etnografía de los grupos indígenas, con el imprescindible $-\mathrm{y}$ notorio cuantitativamente- apoyo lingüístico ${ }^{43}$. Pero las $R e$ laciones del descubrimiento y conquista de la Nueva España y la Historia de Chile prestan atención primordial, más que a la curiosidad que suscita el Nuevo Mundo, más también que a las vivencias derivadas de un asentamiento prolongado, a las acciones de conquista y colonización en las que tan activamente intervinieron sus autores.

\section{REFERENCIAS BIBLIOGRÁfICAS}

Acosta $=$ P. Marín Agreda, Estudio de los indigenismos en la «Historia natural y moral de las Indias» del P. José de Acosta. Tesis doctoral inédita, Madrid, 1992.

Actas $=$ Actas del Congreso sobre «Hernán Cortés y su tiempo», Mérida, 1988.

Alvar = M. Alvar, «Las Relaciones de Yucatán en el siglo xvI», España y América, cara a cara, Valencia, 1975, págs. 145-194.

41 Vid. Góngora Marmolejo, págs. 110-111.

4 Vid. Diaz del Castillo, pág. 37.

4s Para estos aspectos en distintos textos cronísticos, vid. Enguita (Recepción, págs. 201-204). 
Alvar, Español = M. Alvar, «El español de España y el de América», en A. Gallego Morell, Gran Enciclopedia de España y América. VIII. Literatura, Madrid, 1985, páginas $9-22$.

Amado $=$ M. Amado Burgos, «El lenguaje de Panamá», BAP, 3." época, 5, 1970, págs. 87. 103.

Apuntaciones $=$ R. J. Cuervo, Apuntaciones críticas sobre el lenguaje bogotano [1867], Bogotá, 9:" ed., 1955.

Autoridades = Real Academia Española, Diccionario de Autoridades. Edición facsimilar de la de 1726, 3 vols., Madrid, 1969.

Barrera = A. Barrera Vázquez, «Mayismos y voces mayas en el español de Yucatán», IL, IV, 1937, págs. 9-35.

Boyd-Bowman = P. Boyd-Bowman, Léxico bispanoamericano del siglo XVI, Londres, 1972.

Buesa $=\mathrm{T}$. Buesa Oliver, Indoamericanismos léxicos en español, Madrid, 1965.

Cabrera $=$ L. Cabrera, Diccionario de aztequismos, México, 5." ed., 1984.

Calcaño $=\mathrm{J}$. Calcaño, *Canoa», BRAE, 2, 1915, págs. 712-714.

Castellanos = M. Alvar, Juan de Castellanos. Tradición española y realidad americana, Bogotá, 1972.

Cieza de León $=$ K. Baldinger, «Vocabulario de Cieza de León», Lexis, VII-1, 1983, págs. 1-131.

Covarrubias $=\mathrm{S}$. de Covarrubias, Tesoro de la lengua castellana o española [1611], Madrid, 1977.

Cuervo = R. J. Cuervo, «Canoa», Romania, XXX, 1901, págs. 120-122.

$\mathrm{DCECH}=\mathrm{J}$. Corominas (con la colaboración de J. A. Pascual), Diccionario crítico etimológico castellano e bispánico, 6 vols., Madrid, 1980-1991.

Décadas $=$ M.* N. Olmedillas, Pedro Mártir de Angleria y la mentalidad exoticista. Prólogo de M. Ballesteros Gaibrois, Madrid, 1974.

DGA = F. J. Santamaría, Diccionario general de americanismos, 3 vols., México, 1942.

Diario = M. Alvar, «Colón en su aventura», España y América, cara a cara, Valencia, 1975, págs. 49-93.

Díaz del Castillo $=$ M. Alvar, Americanismos en la $*$ Historia $*$ de Bernal Díaz del Castillo [1970], Madrid, 1990.

$\mathrm{DMA}=$ M. A. Morínigo, Diccionario manual de americanismos, Buenos Aires, 1966 [edición revisada, Barcelona, 1985].

DRAE = Real Academia Española, Diccionario de la lengua española, 2 vols., Madrid, 20." ed., 1984.

Encuestas = Encuestas léxicas del habla de Madrid [para el proyecto del Estudio coordinado de la norma lingüistica culta de las principales ciudades de Iberoamérica y de la Península Ibérica]. Ed. de J. C. de Torres, Madrid, 1981.

Enguita = J. M.* Enguita, "Voces nahuas en la Historia general $y$ natural de Gonzalo Fernández de Oviedo: testimonio histórico y pervivencia actual», Actas del Segundo Encuentro de Lingüistas y Filólogos de España y México, Salamanca, 1992 (en prensa).

Enguita, Recepción = J. M." Enguita, «Recepción de indigenismos en algunos textos cronísticos del siglo xvi», El español de América. Actas del III Congreso Internacional de «El español de América», 3 vols., Salamanca, 1991, I, págs. 199-212.

Figueroa $=\mathrm{J}$. Figueroa Lorza, $\approx$ De Castilla y de la tierra», Homenaje a Luis Florez, Bogotá, 1984, págs. $354-377$.

Friederici = G. Friederici, Amerikanistisches Wörterbuch [1947] у Hilfswörterbuch für den Amerikanisten [1926], Hamburgo, 1960. 
Gallego Morell = A. Gallego Morell, Gran Enciclopedia de España y América. VIII. Literatura, Madrid, 1985.

Garcla Blanco $=$ M. García Blanco, «Voces americanas en el teatro de Tirso de Molina», La lengua española en la época de Carlos $V$ y otras cuestiones de Lingüistica y Filolo. gia, Madrid, 1967, págs. 191-212.

Garcla Mouton $=$ P. García Mouton, «Los nombres españoles del maiz», $A L$, XXIV, 1986, págs. 121-146.

Góngora Marmolejo = J. M.* Enguita, «Indoamericanismos léxicos en la Historia de Chile, de Góngora Marmolejo», AUCh. Estudios en honor de Rodolfo Oroz, 5, 1984, págs. 95. 119.

Henríquez Ureña, Ant. $=$ P. Henriquez Ureña, $\star$ Palabras antillanas en el Diccionario de la Academia», RFE, XXII, 1935, págs. 175-186.

Henríquez Ureña, Ind. = P. Henríquez Ureña, Para la bistoria de los indigenismos, Buenos Aires, 1938.

Henríquez Ureña, $S D g o .=$ P. Henríquez Ureña, El español de Santo Domingo, Buenos Aires, vol. V de la $B D H, 1940$.

Hernández Sánchez-Barba $=$ M. Hernández Sánchez-Barba, Introducción a Cartas y documentos, de Hernán Cortés, México, 1963.

Hispanismos = M. A. Morínigo, Hispanismos en el guarani, Buenos Aires, 1931.

Historia = J. M. Enguita, La influencia americana en el léxico de la «Historia general y natural de las Indias», de Gonzalo Fernández de Oviedo. Resumen de tesis doctoral (inédita), Zaragoza, 1980.

La Araucana $=$ M. A. Morínigo, Introducción a La Araucana, de Alonso de Ercilla, Madrid, 1979.

Las Casas = C. Contreras Oyarzun, Visión de América en el léxico de la «Apologética» del padre Las Casas, Madrid, 1984.

Lope Blanch = J. M. Lope Blanch, El léxico indigena en el español de México, México, 2.: ed., 1979.

Lope Blanch, Ant. = J. M. Lope Blanch, «Antillanismos en la Nueva España», Investigaciones sobre Dialectología mexicana, México, 1990, págs. 161-169.

Macazaga = C. Macazaga, Diccionario de la lengua nábuatl, México, 1980.

Malaret = A. Malaret, «Los americanismos en el Diccionario de Autoridades», Universidad Pontificia Bolivariana, XII, 1947, págs. 150-167.

Mejlas $=$ H. A. Mejfas, Préstamos de lenguas indigenas en el español americano del siglo XVII, México, 1980.

MLex. = A. Malaret, Lexicón de fauna y flora [1961], Madrid, 1970.

Molina = A. de Molina, Vocabulario en lengua castellana y mexicana [México, 1571]. Edición facsimilar, Madrid, 1944.

Montes $=\mathrm{J}$. J. Montes Giraldo y M. L. Rodriguez de Montes, El maiz en el habla y la cultura popular de Colombia. Con notas sobre su origen y nombres en lenguas indigenas americanas, Bogotá, 1975.

Morales Padrón = F. Morales Padrón, Gran Enciclopedia de Espafía y América. IV. El Descubrimiento (siglos XV y XVI), Madrid, 1983.

Morínigo, Ind. = M. A. Morínigo, «Indigenismos americanos en el léxico de Lope de Vega», Programa de Filología hispánica, Buenos Aires, 1959, págs. 9-46.

Nebrija = A. de Nebrija, Vocabulario de romance en latín. Transcripción crítica e introducción de G. J. Macdonald, Madrid, 1973.

Neves = A. Neves, Diccionario de americanismos, Buenos Aires, 1973. 
Perea $=$ J. A. y S. Perea, Glosario etimológico taino-español, bistórico y etnográfico, Mayagüez (Puerto Rico), 1941.

Pichardo $=\mathrm{E}$. Pichardo, Diccionario provincial casi razonado de voces $y$ frases cubanas [1875], La Habana, 1985.

Relaciones $(\mathrm{M})=\mathrm{H}$. Cortés, Cartas de relación sobre el descubrimiento y conquista de la Nueva España, en Historiadores primitivos de Indias (I), Madrid, vol. XXII de la Biblioteca de Autores Españoles, 1925, págs. 1-153.

Relaciones $(\mathrm{G})=\mathrm{H}$. Cortés, Cartas de relación de la conquista de la Nueva España y otros documentos. Ed. facsimilar con estudios preliminares de J. Stummvoll, Ch. Gibson y F. Unterkircher, Graz, 1960.

Robelo = C. A. Robelo, Diccionario de axtequismos, Cuernavaca, 1904.

Sala $=$ M. Sala, D. Munteanu, V. Neagu y T. Sandru-Olteanu, El español de América. I. Léxico, 2 vols., Bogotá, 1982.

Santamaría = F. J. Santamaría, Diccionario de mexicanismos, México, 1959.

Simeon $=\mathrm{R}$. Simeon, Diccionario de la lengua nábuatl o mexicana [París, 1855], México, 1977 (con traducción al espafiol).

Sumario $=$ J. M.* Enguita, «Indoamericanismos léxicos en el Sumario de la natural bisto. ria de las Indias», $A L, \mathrm{XIX}, 1979$, págs. 285-304.

Taylor = D. Taylor, «Spanish Canoa and its Congeners», IJAL, 23, 1957, págs. 242-244.

Taylor, Iwana $=$ D. Taylor, «Iwana yuana, iguana», IJAL, 24, 1958, págs. 157-158.

Tesoro $=$ J. M. Lope Blanch, "Los indoamericanismos en el Tesoro de Covarrubias», NRFH, XXVI, 1977, págs. 296-315.

Valdivia $=\mathrm{R}$. Oroz, «La lengua de Pedro de Valdivia», BFUCh, XI, 1959, págs. 133-189.

Zamora Munné $=$ J. C. Zamora Munné, «Amerindian loanwords in general and local varieties of American Spanish», Word, 33, 1982, págs. 159-171.

ZMunné $=$ J. C. Zamora Munné, Indigenismos en la lengua de los conquistadores, San Juan de Puerto Rico, 1976. 